\title{
Protection of Dopamine Neurons by Vibration Training and Up-Regulation of Brain-Derived Neurotrophic Factor in a MPTP Mouse Model of Parkinson's Disease
}

\author{
L. ZHAO' ${ }^{1}$, L. X. HE ${ }^{1}$, S. N. HUANG ${ }^{2}$, L. J. GONG ${ }^{1}$, L. LI' ${ }^{2}$, Y. Y. LV ${ }^{1}$, Z. M. QIAN ${ }^{2}$ \\ ${ }^{1}$ Department of Sports Physiology, Beijing Sport University, Beijing, China, ${ }^{2}$ Laboratory \\ of Neuropharmacology and Department of Neurosurgery, South-West Hospital, Third Military \\ Medical University, Chongqing, China
}

Received January 27, 2014

Accepted March 28, 2014

On-line June 5, 2014

\section{Summary}

It is unknown whether the longer duration of vibration training (VT) has a beneficial effect on Parkinson's disease (PD). And also, the mechanisms underlying the reported sensorimotorimprovement in PD induced by short-duration of VT has not been determined. Here, we investigated the effects of longer duration (4 weeks) of low amplitude vibration (LAV) training on the numbers of dopaminergic neurons in the substantia nigra by immunostaining and the levels of dopamine (DA) and brainderived neurotrophic factor (BDNF) in the striatum by HPLC and ELISA in the chronic MPTP lesion mouse. We demonstrated for the first time that the longer duration of VT could significantly increase the numbers of nigrostriatal DA neurons and the contents of striatal DA and BDNF in the MPTP mice. Our findings implied that longer duration of VT could protect dopaminergic neurons from the MPTP-induced damage probably by upregulating BDNF and also provided evidence for the beneficial effect of longer duration of VT on PD at the cellular and molecular level.

\section{Key words}

Vibration training (VT) - 1-methyl-4-phenyl-1,2,3,6tetrahydropyridine (MPTP) - Parkinson's disease (PD) • Substantia nigra - Striatum - Dopamine (DA) - Tyrosine hydroxylase $(\mathrm{TH}) \bullet$ Brain-derived neurotrophic factor (BDNF)

\section{Corresponding authors}

Z. M. Qian, Laboratory of Neuropharmacology and Department of Neurosurgery, South-west Hospital, The Third Military Medical University, Chongqing 400038 China. E-mail: zmqian1993@gmail.com; L. Zhao, Department of Sports Physiology, Beijing Sport University, Beijing 100084, China. E-mail: zhaolispring@126.com

\section{Introduction}

During the past decade, whole-body vibration (WBV) therapy for the rehabilitation of various conditions has gained popularity (Lau et al. 2011, del Pozo-Cruz et al. 2012). In WBV, the vibration signals are delivered via a vibratory platform or chair to expose a larger part of the body to the stimulation. Recent studies have demonstrated that this modality of training was useful for improving 'Timed up and Go' (TUG) performance, endurance capacity, hormonal production, arterial function, bone mass, balance, proprioception, and health related quality of life (HRQoL) in healthy subjects (Di Loreto et al. 2004, Cardinale et al. 2006, Rehn et al. 2007, Bogaerts et al. 2011, Figueroa et al. 2012).

Parkinson's disease (PD) is a movement disorder that affects millions of people especially in the growing aging population (Pothakos et al. 2009) and has typically varying degrees of muscular weakness, mobility deficits, postural instability, and other motor impairments including rigidity and tremors (Miyai et al. 2000, Bergen et al. 2002, Hirsch et al. 2003). This disorder is mainly caused by degeneration of the nigrostriatal dopamine (DA) neurons in the substantia nigra pars compacta and the resultant deficiency in the neurotransmitter DA at the nerve terminals in the striatum (Nagatsu and Sawada 
2005, Khan et al. 2012). The decreased levels of neurotrophins such as brain-derived neurotrophic factor (BDNF) are found in the nigrostriatal region of postmortem brains and/or in the ventricular or lumbar cerebrospinal fluid (CSF) of the patients with PD, and also in the 1-methyl-4-phenyl-1,2,3,6-tetrahydropyridine (MPTP) and 6-hydroxydopamine (6-OHDA) animal models of PD (Nagatsu and Sawada 2005).

In view of the many neuromotor deficits commonly observed in this disorder, it has been believed that patients with PD may be potential beneficiaries of WBV (Lau et al. 2011). However, the reported findings were conflicting. A single session of WBV (five 1-min bouts) has been demonstrated to be able to cause a significant improvement of gait that is measured using the TUG test in comparison to standing exercises (Haas et al. 2006, King et al. 2009), but longer duration of WBV (3-5 weeks) did not result in better sensorimotor outcomes or significant results in comparison with physical therapy in body balance or signs and symptoms measured with the Unified Parkinson's Disease Rating Scale (UPDRS) (Ebersbach et al. 2008, Arias et al. 2009). These results showed that it has not been confirmed whether the longer duration of WBV has a beneficial effect on signs and symptoms of Parkinson's disease (Lau et al. 2011, del Pozo-Cruz et al. 2012, Sitjà et al. 2012). And also, the mechanisms underlying the reported improvement in patients with PD induced by short-duration of vibration training are not well determined.

The nigrostriatal pathway is involved in the control of movement. We hypothesized that VT, no matter short or longer periods, should have a favorable effect on the pathway in PD brain if the training has a beneficial effect on sensorimotor outcomes. We therefore investigated the effects of 4 weeks of low amplitude vibration training with high or low frequency on the numbers of dopaminergic neurons in the substantia nigra by immunostaining and the levels of DA and BDNF in the striatum by HPLC and ELISA in the chronic MPTP lesion mouse. We demonstrated for the first time that longer duration (4 weeks) of vibration training could significantly increase the number of nigrostriatal DA neurons and the contents of striatal DA and BDNF in the MPTP mice, indicating that VT have a favorable effect on the nigrostriatal pathway in PD brain. Our findings implied that longer duration of VT could protect dopaminergic neurons from the MPTP-induced damage probably by upregulating BDNF and also provided evidence for the beneficial effect of longer duration of
VT on PD at the cellular and molecular level.

\section{Materials and Methods}

\section{Materials}

MPTP·HCl (1-methyl-4-phenyl-1,2,3,6-tetrahydropyridine $\cdot \mathrm{HCl}$ ) and $\mathrm{DA}$ (dopamine) standard sample were purchased from Sigma Chemical, St. Louis, MO, USA. Mouse monoclonal anti-tyrosine hydroxylase and DAB kit were got from Abcam, Cambridge, UK. BDNF (brain-derived neurotrophic factor) ELISA protease assay kit was obtained from China Co. Ltd (an agent of R\&D Systems), Shanghai, PRC. DA standard sample was dissolved in $0.1 \mathrm{M}$ perchloric acid at an initial concentration of $1 \mathrm{mg} / \mathrm{ml}$. The MPTP. $\mathrm{HCl}$ was dissolved in physiological saline $(0.9 \%)$ at a concentration of $2.0 \mathrm{mg} / \mathrm{ml}$.

\section{Mice and treatments}

Male C57BL mice weighing 25-30 g were supplied by the Military Science Academy of Beijing, housed in pairs in stainless steel cages at $22 \pm 2{ }^{\circ} \mathrm{C}$ with a relative humidity of $50-70 \%$, and provided free access to food (the Laboratory Rodent Diet; PMI Nutrition International Inc., Brentwood, MO) and distilled water at all times. Rooms were in a cycle of 12-h light (0700$1900 \mathrm{~h}$ ) and 12-h darkness (from 1900-0700 h). The animals were randomly assigned to the following four groups: (1) Normal control group ( $n=6)$, (2) MPTP group ( $n=6)$, (3) MPTP+LAV-LF (low amplitude and low frequency vibration, $n=7$ ), and (4) MPTP+LAV-HF (low amplitude and high frequency vibration, $n=6$ ). The mice in MPTP and normal control groups were given two intraperitoneally injections of MPTP (30 mg/kg) at 12-h intervals per day for 7 consecutive days or a comparable volume of $0.9 \%$ saline, respectively. The animals in MPTP+LAV-LF and MPTP+LAV-HF groups were treated with vibration training for four weeks, five days each week after the injection of MPTP. After received different treatments, the mice were decapitated and the brains were removed for all relevant measurements. Beijing Laboratory Animal Welfare and Ethics Committee and The Animal Research Ethics Committees of Beijing Sports University approved the experimental procedures of this study.

\section{Kuribara's grid test}

Twenty minutes after the last injection of MPTP, all mice went through Kuribara's grid test as described by 
Kuribara et al. (1977). The scoring scale is as follows: 0-4 s gets none point, 5-9 s 1 point, 10-14 s 2 points, 15-19 s 3 points, 20-24 s 4 points, 25-29 s 5 points and those above $30 \mathrm{~s}$ scores 6 points. Each mouse was tested three times and evaluated on an average point scale. A PD model is successfully built up only if the average point is below 3 points. Of all the 26 mice that received MPTP, only 19 of them successfully became PD mice. The score of each group in grid test before vibration training is listed in Table 1.

Table 1. Scores of Kuribara's grid test.

\begin{tabular}{lccc}
\hline Group & $\mathbf{n}$ & $\begin{array}{c}\text { Score } \\
\text { (point) }\end{array}$ & $\begin{array}{c}\mathbf{P} \\
\text { (vs. Control) }\end{array}$ \\
\hline Control & 6 & $6.00 \pm 0.00$ & \\
$M P T P$ & 6 & $1.50 \pm 1.29$ & $<0.01$ \\
$M P T P+L A V-L F$ & 7 & $1.40 \pm 1.52$ & $<0.01$ \\
$M P T P+L A V-H F$ & 6 & $1.33 \pm 1.17$ & $<0.01$ \\
\hline
\end{tabular}

All mice went through Kuribara's grid test twenty minutes after the last injection of MPTP before vibration training was conducted. Data were expressed mean \pm S.E.M.

\section{Vibration training}

A vibrational platform (Columbus Instruments, Columbus, $\mathrm{OH}, \mathrm{USA}$ ) was utilized for vibration training. The mice allowed roaming freely on the platform. Based on the findings of our preliminary experiments, vibration frequency was chosen at $10 \mathrm{~Hz}$ (LF) or $30 \mathrm{~Hz}$ (HF) with amplitude of $5 \mathrm{~mm}$. The protocol was executed as the following: a session/day, 15 repeats/session, $1 \mathrm{~min} /$ repeat, with $1 \mathrm{~min}$ of rest in between. The mice in normal control and MPTP groups did not vibrate; however, they were transported daily to the platform so that they were exposed to the same environment as the vibration group of animals.

Analysis of the number of TH-positive neurons in the substantia nigra

Brains were cut into $25 \mu \mathrm{m}$ coronal sections with a freezing microtome (Thermo Scientific, Germany) and stored in cryoprotectant solution at $-20^{\circ} \mathrm{C}$. Every 6th sections containing the substantia nigra region were subject to immunostaining. Briefly, sections were rinsed in phosphate buffered saline (PBS) and incubated with mouse monoclonal anti-tyrosine hydroxylase (1:3000) at $4{ }^{\circ} \mathrm{C}$ for $12 \mathrm{~h}$. After washing with PBS for 3 times, the sections were incubated with the rabbit polyclonal anti- mice secondary antibody (1:500) at room temperature for $1 \mathrm{~h}$. After rinsing in PBS, the immunocomplex was visualized using DAB kit. The total numbers of THpositive cells were counted in the sections using the optical fractionator method.

\section{HPLC analysis of dopamine}

Striatal tissues for analysis were homogenized in $0.4 \mathrm{~N}$ perchloric acid and centrifuged at $12,000 \mathrm{~g}$ to separate precipitated protein. The protein pellet was resuspended in $0.5 \mathrm{~N} \mathrm{NaOH}$ and the total protein concentration determined using a Biotek Model Elx800 microplate reader (Biotek Instruments Wincoski, VT) with KCjunior software. The concentrations of dopamine were assayed by HPLC with electrochemical detection as previously described (Xie et al. 2003). The electrochemical detector was an ESA model Coularray 5600A with a four-channel analytical cell with three set potentials at $-100,50$, and $220 \mathrm{mV}$.

Immunoassay of brain-derived neurotrophic factor (BDNF)

BDNF levels in the striatum tissues were determined by a sandwich enzyme-linked immunosorbent assay (ELISA). For extraction, tissue samples of the striatum were sonicated to homogeneity on ice in $10 \mathrm{vol} / \mathrm{wt}$ of an acidic extraction buffer [0.05 M sodium acetate (Merck, Darmstadt, Germany), pH 4.0, $1 \mathrm{M} \mathrm{NaCl}$ (Merck), $0.1 \%$ Triton X-100 (Sigma, Buchs, Switzerland), 1 \% BSA (Europa Bioproducts, Cambridge, UK), complete protease inhibitor cocktail (Roche, Mannheim, Germany)], and subsequently centrifuged for $30 \mathrm{~min}$ at $100,000 \mathrm{~g}$ and $4{ }^{\circ} \mathrm{C}$. The clear supernatants were collected, stored at $-80^{\circ} \mathrm{C}$, and centrifuged again for $30 \mathrm{~min}$ at $20,000 \mathrm{~g}$ and $4^{\circ} \mathrm{C}$ immediately before use.

\section{Statistical analysis}

Statistical analysis was performed using SPSS version 14.0 for Windows (SPSS, Chicago, IL) or InStat software (GraphPad Software). Differences in behavioral tests between groups were analyzed using repeatedmeasures ANOVA with the between subjects factors being lesion (saline or MPTP) and intervention and the within subject factor being time. For HPLC analysis and immunocytochemistry staining, a two-way ANOVA was performed to compare the different groups and examine for significant interactions. Within-subject effects were performed using the Huynh-Feldt correction for sphericity. For all analyses, a significance level of $\mathrm{p}<0.05$ was used. 

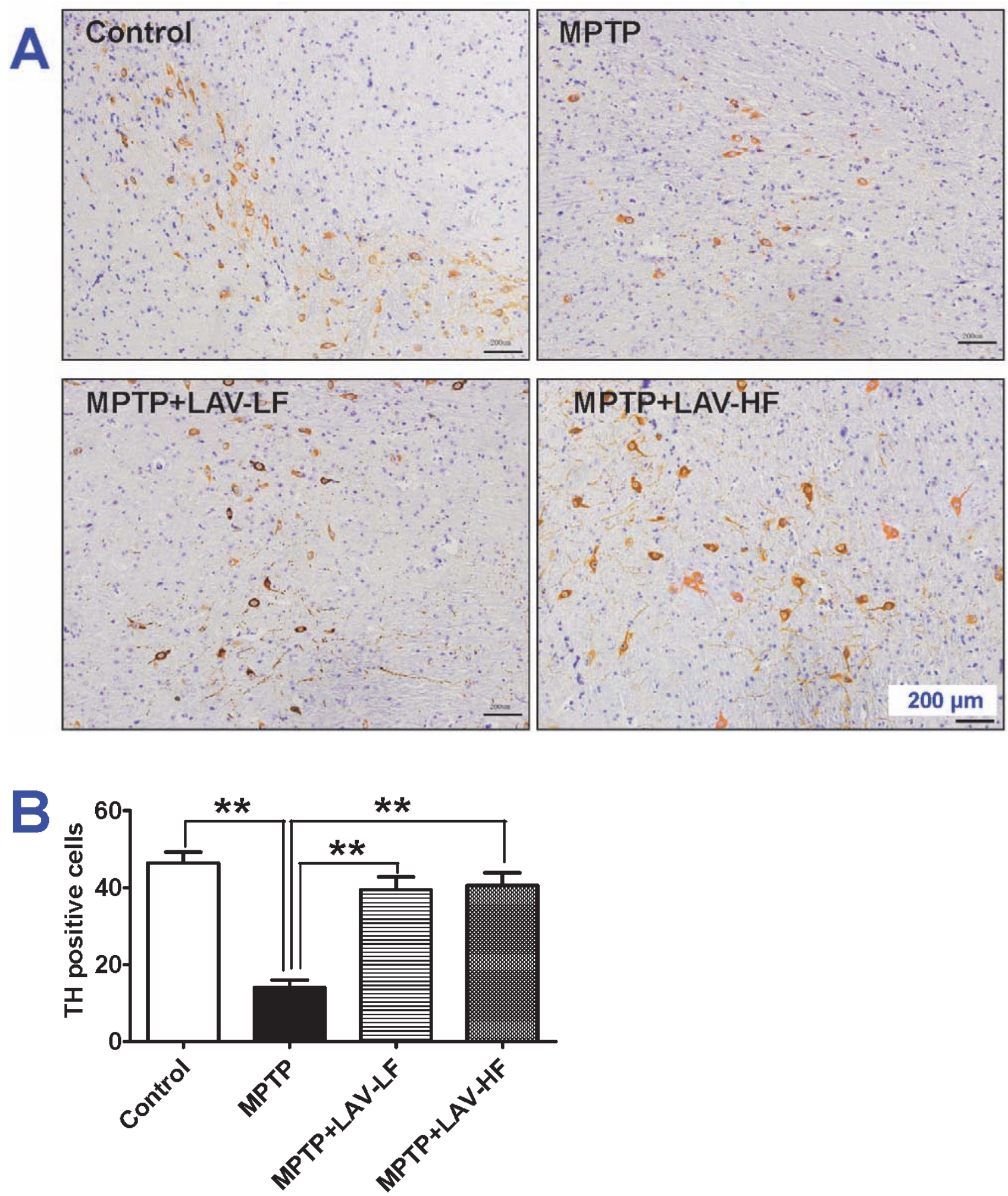

Fig. 1. Low amplitude vibration significantly increased the numbers of dopaminergic neurons in the substantia nigra of MPTP mice. After the designed treatments, the mice were decapitated and perfused, the brains were removed, and the numbers of TH positive cells in the substantia nigra were then determined using immunohistochemical staining as described in "Methods and materials". A: A representative immunohistochemical staining, Scale bars $=200 \mu \mathrm{m}, \mathbf{B}$ : TH positive cells. Data were presented as mean \pm SEM (control: $n=6$; MPTP: $n=6$; MPTP+LAV-LF (low amplitude and low frequency vibration): $n=7$, and MPTP+LAV-HF (low amplitude and high frequency vibration): $n=6)$. ${ }^{* *} P<0.01$ versus the corresponding value 


\section{Results}

Low amplitude vibration significantly increased the numbers of dopaminergic neurons in the substantia nigra of MPTP mice

To find out the effects of low amplitude vibration on dopaminergic neurons in the brain, we measured the number of $\mathrm{TH}$ positive cells in the substantia nigra using immunohistochemical staining in mice received different treatments. It was found that MPTP treatment induced a significant reduce in the numbers of $\mathrm{TH}$ immunoreactive nerve fibers in mice $(\mathrm{P}<0.01$ vs. control) (Fig. $1 \mathrm{~A}$ and $\mathrm{B})$. However, the numbers of TH positive cells in MPTP plus LAV-LF and MPTP plus LAV-HF groups were significantly higher than those in the MPTP mice $(\mathrm{p}<0.01)$. No significant differences in $\mathrm{TH}$ positive cells were observed between the mice treated with MPTP plus low amplitude high frequency vibration and the mice received MPTP plus low amplitude low frequency vibration. These findings indicated that low amplitude vibration, no matter with low or high frequency, could significantly increase the numbers of dopaminergic neurons in the substantia nigra of the MPTP mice.

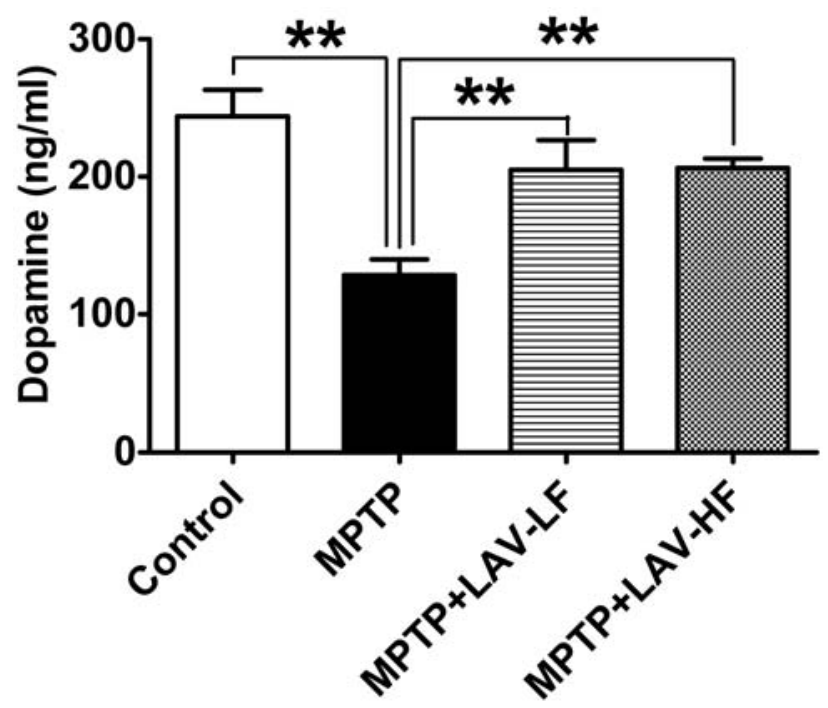

Fig. 2. Low amplitude vibration significantly increased the levels of dopamine in the striatum of MPTP mice. After the completion of all experimental procedures, the mice were decapitated and perfused, the brains were removed, and the contents of striatal dopamine $(\mathrm{ng} / \mathrm{ml})$ were assayed by HPLC analysis as described in "Methods and materials". Data were presented as mean \pm SEM (control: $n=6$; MPTP: $n=6$; MPTP+LAV-LF (low amplitude and low frequency vibration): $n=7$, and MPTP+LAV-HF (low amplitude and high frequency vibration): $n=6) . * * P<0.01$ versus the corresponding value
Low amplitude vibration significantly increased the levels of dopamine in the striatum of MPTP mice

HPLC analysis demonstrated that four weeks of low amplitude vibration induced a significant effect on the contents of dopamine in the striatum of the MPTP mice (Fig. 2). MPTP treatment led to a significant reduction in dopamine content (128.33 $\pm 15.68 \mathrm{ng}$ dopamine/ml) compared with the control (saline) group (260.56 $\pm 24.44 \mathrm{ng}$ dopamine/ml), which corresponded to $73 \%$ depletion. Treatment with low amplitude vibration induced a significant increase in the contents of striatal dopamine in the MPTP mice, showing a beneficial effect of low amplitude vibration on striatal dopamine in MPTP mice. The contents of striatal dopamine in the MPTP+LAV-LF (204.97 \pm 25.11 ng dopamine/ml) and MPTP+LAV-HF (206.37 \pm 8.99 ng dopamine/ml) mice were significantly higher than those in the mice treated with MPTP only. This showed that low amplitude vibration could lead to about $52 \%$ recovery of striatal dopamine in MPTP mice. No significant differences were found in striatal dopamine levels between MPTP plus LAV-LF and MPTP plus LAVHF mice, suggesting that the frequency of vibration was not an important factor in the determination of effects of low amplitude vibration on striatal dopamine.

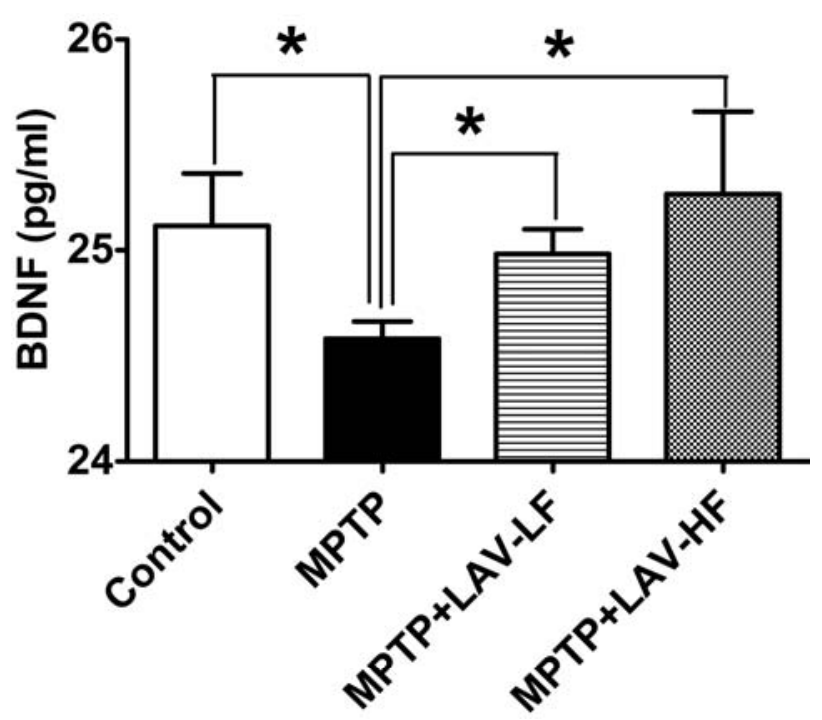

Fig. 3. Low amplitude vibration significantly increased the contents of BDNF in the striatum of MPTP mice. After the completion of all experimental procedures, the mice were decapitated and perfused, the brains were removed and the contents of BDNF $(\mathrm{pg} / \mathrm{ml})$ in the striatum were determined using ELISA analysis as described in "Methods and materials". Data were presented as mean \pm SEM (control: $n=6 ;$ MPTP: $n=6$; MPTP+LAV-LF (low amplitude and low frequency vibration): $n=7$, and MPTP+LAV-HF (low amplitude and high frequency vibration): $\mathrm{n}=6) . * \mathrm{P}<0.05$ versus the corresponding value 
Low amplitude vibration significantly increased the contents of BDNF in the striatum of MPTP mice

To determine whether BDNF plays a role in the survival of dopaminergic neurons, we measured the contents of BDNF in the striatum using ELISA. In consistent with the effects of MPTP and low amplitude vibration on the numbers of dopaminergic neurons in the substantia nigra and the contents of striatal dopamine, MPTP also induced a significant reduction in the levels of BDNF compared with the control (saline) mice $(\mathrm{P}<0.05)$. In addition, low amplitude vibration led to a significant enhancement in levels of BDNF in the MPTP mice (Fig. 3). The BDNF contents in the MPTP plus LAV-LF group were higher than those in the MPTP plus LAV-HF mice although there was no significant difference between these two groups.

\section{Analysis of the correlation relationship}

The analysis of the relationship between the contents of BDNF in striatum and the numbers of $\mathrm{TH}$ positive cells in the substantia nigra was conducted by plotting the values for these two measurements against one another. A positive correlation was found between these two measurements in the Control $(\mathrm{r}=0.78, \mathrm{p}<0.01)$; MPTP $\quad(r=0.78, \quad \mathrm{p}<0.01), \quad$ MPTP+LAV-LF $\quad(r=0.74$, $\mathrm{p}<0.01)$ and MPTP+LAV-HF $(\mathrm{r}=0.84, \mathrm{p}<0.01)$ groups. The analysis on the relationship between the numbers of $\mathrm{TH}$ positive cells in the substantia nigra and the concentrations of dopamine in the striatum also showed the existence of a positive correlation between these two measurements in the Control $(\mathrm{r}=0.78, \mathrm{p}<0.01)$; МPTP $(\mathrm{r}=0.91, \mathrm{p}<0.01), \mathrm{MPTP}+\mathrm{LAV}-\mathrm{LF}(\mathrm{r}=0.83, \mathrm{p}<0.01)$ and MPTP+LAV-HF $(r=0.84, \mathrm{p}<0.01)$ groups.

\section{Discussion}

At present, it is unknown whether the longer duration of WBV has a beneficial effect on signs and symptoms of Parkinson's disease (Lau et al. 2011, del Pozo-Cruz et al. 2012, Sitjà et al. 2012). Although a single session of WBV (five 1-min bouts) has been demonstrated to be able to cause a significant improvement of gait that is measured using the TUG test (Haas et al. 2006, King et al. 2009), the relevant mechanisms has not been determined. In the present study, we therefore investigated effects of 4 weeks (longer duration) of low amplitude vibration with low or high frequency on the dopaminergic neurons and the DA and BDNF contents in the brain of a MPTP Mouse Model of Parkinson's disease. We demonstrated for the first time that longer duration of low amplitude vibration could induce a significant increase in the numbers of dopaminergic neurons in the substantia nigra as well as the levels of dopamine and BDNF in the striatum of the MPTP mice. Our findings implied that longer duration of VT could protect dopaminergic neurons from the MPTPinduced damage probably by upregulating BDNF and also provide evidence at the cellular and molecular level for the existence of the beneficial effects of longer duration of VT on PD.

The significant increase in the numbers of dopaminergic neurons in the substantia nigra in the MPTP mice treated with low amplitude vibration implied that low amplitude vibration has the role to protect dopaminergic neurons from the MPTP-induced damage. Our findings also showed that there was a significant increase in BDNF in the striatum in MPTP mice treated with low amplitude vibration. BDNF is a small dimeric protein that is particularly abundant in the hippocampus and cerebral cortex. This endogenous "neuroprotectant" (Deogracias et al. 2012) is anterogradely transported from the hippocampus and cerebral cortex to its striatal target via the corticostriatal afferents (Altar et al. 1997, Huang and Reichardt 2001, Baquet et al. 2004). This factor has been shown to promote the survival of all major neuronal types affected in PD and other neurodegenerative diseases (Baquet et al. 2004, Zuccato and Cattaneo 2007). The decreased neurotrophins including BDNF has been demonstrated in the nigrostriatal region of postmortem brains and/or in the ventricular or lumbar cerebrospinal fluid (CSF) of the PD patients and also the MPTP- and 6-OHDA animal PD models (Nagatsu and Sawada 2005). And the decreased BDNF has also been considered as one of causes for the degeneration of the DA neurons in the substantia nigra pars compacta and the loss of nerve terminals accompanied by DA deficiency in the striatum that are responsible for most of the movement disturbances in the PD patient (Nagatsu et al. 2000). Therefore, it is highly likely that protective effects of vibration training on dopaminergic neurons in the PD mice might be at least partly due to the significant increase in BDNF in the striatum. This possibility was also strongly supported by the existence of a positive correlation between the contents of BDNF in striatum and the numbers of $\mathrm{TH}$ positive cells in the substantia nigra.

Tyrosine hydroxylase is an enzyme responsible for the rate-limiting step in dopamine biosynthesis 
(Cartier et al. 2010, Prandovszky et al. 2011). The loss of dopaminergic or TH positive neurons in substantia nigra is always accompanied by the decreased DA content in striatum in the PD patients (Toulouse and Sullivan 2008, Hilker et al. 2012). In addition, the analysis on relationship between the numbers of $\mathrm{TH}$ positive cells in the substantia nigra and the concentrations of dopamine in the striatum demonstrated the existence of a positive correlation between these two measurements in all four groups. The positive correlation and also the reduction in TH positive neurons with DA contents in the PD patients suggested that the significant increase in the levels of dopamine in the striatum in the MPTP mice treated with low amplitude vibration probably resulted from the increased numbers of dopaminergic neurons in the substantia nigra.

Our data showed that four weeks of vibration training almost completely prevented the MPTP-induced loss of DA neurons in the substantia nigra and reduction of DA levels in the striatum. In addition to BNDF, we did not examine the contents of other neurotrophic factors such as nerve growth factor (NGF), cytokines including tumor necrosis factor (TNF)-alpha and transforming growth factor (TFG)-alpha and the activities of caspase-1 and caspase- 3 in the MPTP mice treated with different treatments. To better understanding the mechanisms underlying the improvement in sensorimotor function induced by short- or longer-duration of vibration training, further investigations on the changes of these parameters are absolutely needed in the MPTP mice treated with or without vibration training.

In the present study, we also found that there were no significant differences in the numbers of dopaminergic neurons and the levels of dopamine and BDNF in the brain between the MPTP mice treated with LAV-LF or LAV-HF. This indicated that frequency is not a key factor under our experimental conditions. The findings also remained us to consider the possibility that the amplitude and/or frequency might be not the optimal in those studies where longer duration of WBV (3-5 weeks) did not result in a better sensorimotor outcome in the PD patients (Ebersbach et al. 2008, Arias et al. 2009). Therefore, further studies about the effects of different amplitude and/or frequency and also duration on PD are also needed. These studies will provide important information for the establishment of the clinical efficacy of vibration training in improving sensorimotor function in patients with PD.

\section{Conflict of Interest}

There is no conflict of interest.

\section{Acknowledgements}

This work was supported by Program for New Century Excellent Talents in University, National 973 Programs (2011CB510004) and the National Natural Science Foundation of China (No. 31271132, 31040044, and 31271278). We declare that we have no financial interests. L.Z. and Z.M.Q. conceived, organized and supervised the study; L.X.H., S.N.H., L.G., L.L. and Y.L. performed the experiments; L.Z. and Z.M.Q. contributed to the analysis and interpretation of data, prepared and wrote the manuscript.

\section{References}

ALTAR CA, CAIN N, LIVEN T, JUDAS M, CONNER JM, ACHESON AL, LINDSAY RM, WIGAND SJ: Anterograde transport of brain-derived neurotrophic factor and its role in the brain. Nature 389: 856-860, 1997.

ARIAS P, CHOUZA M, VIVAS J, CUDEIRO J: Effect of whole body vibration in Parkinson's disease: a controlled study. Mov Disord 24: 891-898, 2009.

BAQUET ZC, GORSKI JA, JONES KR: Early striatal dendrite deficits followed by neuron loss with advanced age in the absence of anterograde cortical brain-derived neurotrophic factor. J Neurosci 24: 4250-4258, 2004.

BERGEN JL, TOOLE T, ELLIOTT RG, WALLACE B, ROBINSON K, MAITLAND CG: Aerobic exercise intervention improves aerobic capacity and movement initiation in Parkinson's disease patients. NeuroRehabilitation 17: 161-168, 2002.

BOGAERTS A, DELECLUSE C, BOONEN S, CLAESSENS AL, MILISEN K, VERSCHUEREN SM: Changes in balance, functional performance and fall risk following whole body vibration training and vitamin D supplementation in institutionalized elderly women. A 6 month randomized controlled trial. Gait Posture 33: 466-472, 2011. 
CARDINALE M, LEIPER J, ERSKINE J, MILROY M, BELL S: The acute effects of different whole body vibration amplitudes on the endocrine system of young healthy men: A preliminary study. Clin Physiol Funct Imaging 26: 380-384, 2006.

CARTIER EA, PARRA LA, BAUST TB, QUIROZ M, SALAZAR G, FAUNDEZ V, EGAÑA L, TORRES GE: A biochemical and functional protein complex involving dopamine synthesis and transport into synaptic vesicles. J Biol Chem 285: 1957-1966, 2010.

DEL POZO-CRUZ B, ADSUAR JC, PARRACA JA, DEL POZO-CRUZ J, OLIVARES PR, GUSI N: Using whole-body vibration training in patients affected with common neurological diseases: a systematic literature review. J Altern Complement Med 18: 29-41, 2012.

DEOGRACIAS R, YAZDANI M, DEKKERS MP, GUY J, IONESCU MC, VOGT KE, BARDE YA: Fingolimod, a sphingosine-1 phosphate receptor modulator, increases BDNF levels and improves symptoms of a mouse model of Rett syndrome. Proc Natl Acad Sci USA 109: 14230-14235, 2012.

DI LORETO C, RANCHELLI A, LUCIDI P, MURDOLO G, PARLANTI N, DE CICCO A, TSARPELA O, ANNINO G, BOSCO C, SANTEUSANIO F, BOLLI GB, DE FEO P: Effects of whole-body vibration exercise on the endocrine system of healthy men. J Endocrinol Invest 27: 323-327, 2004.

EBERSBACH G, EDLER D, KAUFHOLD O, WISSEL J: Whole body vibration versus conventional physiotherapy to improve balance and gait in Parkinson's disease. Arch Phys Med Rehabil 89: 399-403, 2008.

FIGUEROA A, GIL R, WONG A, HOOSHMAND S, PARK SY, VICIL F, SANCHEZ-GONZALEZ MA: Wholebody vibration training reduces arterial stiffness, blood pressure and sympathovagal balance in young overweight/obese women. Hypertens Res 35: 667-672. 2012.

HAAS CT, TURBANSKI S, KESSLER K, SCHMIDTBLEICHER D: The effects of random whole-body-vibration on motor symptoms in Parkinson's disease. NeuroRehabilitation 21: 29-36, 2006.

HILKER R, PILATUS U, EGGERS C, HAGENAH J, ROGGENDORF J, BAUDREXEL S, KLEIN JC, NEUMAIER B, FINK GR, STEINMETZ H, KLEIN C, HATTINGEN E: The bioenergetic status relates to dopamine neuron loss in familial PD with PINK1 mutations. PLoS One 7: e51308, 2012.

HIRSCH MA, TOOLE T, MAITLAND CG, RIDER RA: The effects of balance training and high-intensity resistance training on persons with idiopathic Parkinson's disease. Arch Phys Med Rehabil 84: 1109-1117, 2003.

HUANG EJ, REICHARDT LF: Neurotrophins: roles in neuronal development and function. Annu Rev Neurosci 24: 677-736, 2001.

KHAN W, PRIYADARSHINI M, ZAKAI HA, KAMAL MA, ALAM Q: A brief overview of tyrosine hydroxylase and $\alpha$-synuclein in the Parkinsonian brain. CNS Neurol Disord Drug Targets 11: 456-462, 2012.

KING LK, ALMEIDA QJ, AHONEN H: Short term effects of vibration therapy on motor impairments in Parkinson's disease. NeuroRehabilitation 25: 297-306, 2009.

KURIBARA H, HIGUCHI Y, TADOKORO S: Effects of central depressants on rota-rod and traction performances in mice. Japan J Pharmacol 27: 117-126, 1977.

LAU RW, TEO T, YU F, CHUNG RC, PANG MY: Effects of whole-body vibration on sensorimotor performance in people with Parkinson disease: a systematic review. Phys Ther 91: 198-209, 2011.

MIYAI I, FUJIMOTO Y, UEDA Y, YAMAMOTO H, NOZAKI S, SAITO T, KANG J: Treadmill training with body weight support: its effect on Parkinson's disease. Arch Phys Med Rehabil 81: 849-852, 2000.

NAGATSU T, SAWADA M: Inflammatory process in Parkinson's disease: role for cytokines. Curr Pharm Des 11: 999-1016, 2005.

NAGATSU T, MOGI M, ICHINOSE H, TOGARI A: Changes in cytokines and neurotrophins in Parkinson's disease. J Neural Transm Suppl 60: L277-L290, 2000.

POTHAKOS K, KURZ MJ, LAU YS: Restorative effect of endurance exercise on behavioral deficits in the chronic mouse model of Parkinson's disease with severe neurodegeneration. BMC Neurosci 10: 6 doi:10.1186/14712202-10-6, 2009.

PRANDOVSZKY E, GASKELL E, MARTIN H, DUBEY JP, WEBSTER JP, MCCONKEY GA: The neurotropic parasite Toxoplasma gondii increases dopamine metabolism. PLoS One 6: e23866, 2011.

REHN B, LIDSTROM J, SKOGLUND J, LINDSTROM B: Effects on leg muscular performance from whole-body vibration exercise: a systematic review. Scand J Med Sci Sports 17: 2-11, 2007. 
SITJÀ RABERT M, RIGAU COMAS D, FORT VANMEERHAEGHE A, SANTOYO MEDINA C, ROQUÉ I FIGULS M, ROMERO-RODRÍGUEZ D, BONFILL COSP X: Whole-body vibration training for patients with neurodegenerative disease. Cochrane Database Syst Rev 2:CD009097 doi:10.1002/14651858.CD009097.pub2. 2012.

TOULOUSE A, SULLIVAN AM: Progress in Parkinson's disease - Where do we stand? Prog Neurobiol 85: 376-392, 2008.

XIE JX, JIANG H, CHEN WF, QIAN ZM: Dopamine release rather than content in the caudate putamen is associated with behavioral changes in the iron rat model of Parkinson's disease. Exp Neurol 182: 483-489, 2003.

ZUCCATO C, CATTANEO E: Role of brain-derived neurotrophic factor in Huntington's disease. Prog Neurobiol 81: 294-330, 2007. 